SPARK SPECTROGRAPHIC CHARACTERIZATION OF URANIUM METAL BY PART SURFACE SENSITIZATION

H. G. King

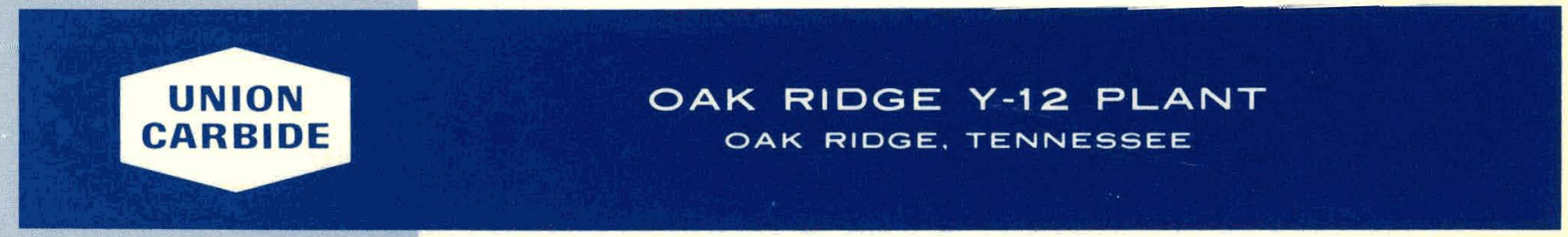

prepared for the U.S. ENERGY RESEARCH AND DEVELOPMENT ADMINISTRATION under U.S. GOVERNMENT Contract W-7405 eng 26 


\section{DISCLAIMER}

This report was prepared as an account of work sponsored by an agency of the United States Government. Neither the United States Government nor any agency Thereof, nor any of their employees, makes any warranty, express or implied, or assumes any legal liability or responsibility for the accuracy, completeness, or usefulness of any information, apparatus, product, or process disclosed, or represents that its use would not infringe privately owned rights. Reference herein to any specific commercial product, process, or service by trade name, trademark, manufacturer, or otherwise does not necessarily constitute or imply its endorsement, recommendation, or favoring by the United States Government or any agency thereof. The views and opinions of authors expressed herein do not necessarily state or reflect those of the United States Government or any agency thereof. 


\section{DISCLAIMER}

Portions of this document may be illegible in electronic image products. Images are produced from the best available original document. 
Reference to a company or product name does not imply approval or recommendation of the product by Union Carbide Corporation or the U.S. Energy Research and Development Administration to the exclusion of others that may meet specifications.

Printed in the United States of America. Available from

National Technical Information Service

U.S. Department of Commerce

5285 Port Royal Road, Springfield, Virginia 22161

Price: Printed Copy \$4.00; Microfiche $\$ 2.25$

This report was prepared as an account of work sponsored by the United States Government. Neither the United States nor the Energy Research and Development Administration, nor any of their employees, nor any of their contractors, subcontractors, or their employees, makes any warranty, express or implied, or assumes any legal liability or responsibility for the accuracy, completeness or usefulness of any information, apparatus, product or process disclosed, or represents that its use would not infringe privately owned rights. 


\title{
SPARK SPECTROGRAPHIC CHARACTERIZATION OF URANIUM METAL BY PART SURFACE SENSITIZATION
}

\author{
H. G. King
}

Laboratory Development Department

Y-12 Development Division

\begin{abstract}
This report was prepared as an account of work sponsored by the United States Government. Neither the. United States nor the United States Energy Research and Development Administration, nor any of their employees, nor any of the subcontractors, or their warrantor, or their emplnyers, maksi any Warranty, oxpitess or implied, or assimes any legal liability or responsibility for the accuracy, completeness or usefulness of any infoumation, apparatus, product or process disclosed, or represents that its use would or infringe privately owned rights.
\end{abstract}

\section{Oak Ridge Y-12 Plant}

P. O. Box Y, Oak Ridge, Tennessee 37830

Prepared for the US Energy Research and Development Administration Under US Government Contract W-7405-eng-26 


\begin{abstract}
Further studies of the in-situ spectrographic characterization of uranium metal have resulted in changes in methodology which reduce spectral background and improve the sensitivity of the method. The anode spot is sensitized by thermoelectrical bombardment from the ammonium bifluóride-packed cathode. Detection limits oan be lowered by as much as twofold, and a more readable spectrogram is obtained.
\end{abstract}




\section{CONTENTS}

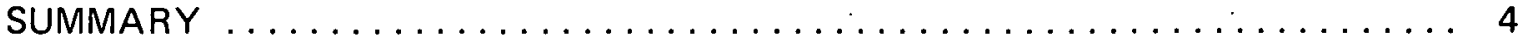

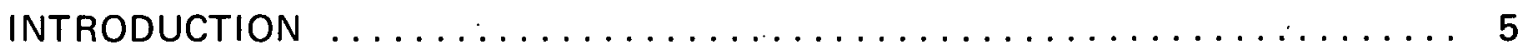

CHARACTERIZATION OF URANIUM METAL $\ldots \ldots \ldots \ldots \ldots \ldots \ldots \ldots, 6$

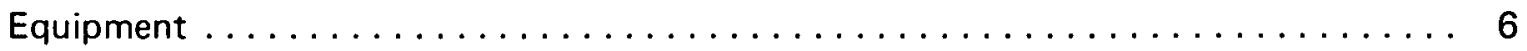

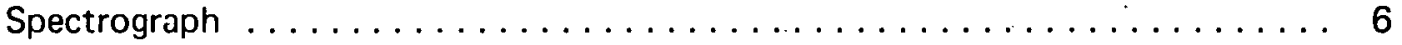

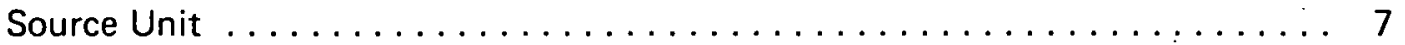

Materials...................................... 7

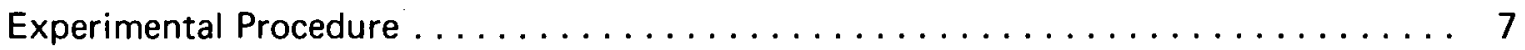

General Considerations ........................ 7

Preliminary Investigations $\ldots \ldots \ldots \ldots \ldots \ldots \ldots \ldots \ldots \ldots \ldots \ldots \ldots$

Methodology ................................. 9

Sensitization Phenomenon $\ldots \ldots \ldots \ldots \ldots \ldots \ldots \ldots \ldots \ldots \ldots, 9$

Discussion ......................................... 11

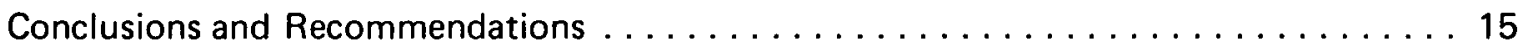

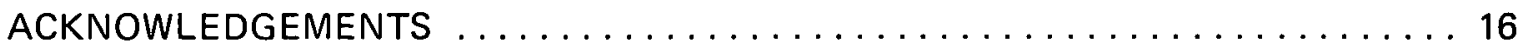

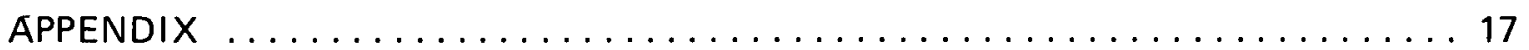

In-Situ Spark Snectrochemical Characterization of Uranium Melal

by Anode Sensitization ............................. 17 


\section{SUMMARY}

A relatively sensitive spectrographic method has been developed for the characterization of impurities in semifinished and in-stream uranium parts. The cratered graphite cathode ${ }^{(a)}$ in a high-frequency spark discharge is packed with $40 \mathrm{mg}$ of ammonium bifluorlde $\left(\mathrm{NH}_{4} \mathrm{HF}_{2}\right)$ which serves to generate a carrier action at the part surface on which the spark column impinges. The volatile impurity fluorides are rapidly released into the spark rolumn from the uranium metal to provide greater sensitivity and to provide for better plate reading.

The corrosion effects on the part surface were studied, and it was found that no corrosion centers were formed, although the part Is very slighluly alfecled dimensionally. Additional surface explorations were made with an electron microprobe to mure cumpletely characterize the sensitizing phenomenon.

Sensitivity increases were evaluated by a simple comparison of the spectra taken from the graphite cathode and that obtained by this method. Increases in the sensitivity of essentially all elements sought were observed.

(a) The convention "cathode" is used to indicate phase as distinguished from ground. 


\section{INTRODUCTION}

While the method developed previously for the in-situ spark spectrographic analysis of uranium metal for impurities does not suffer from intolerable levels of matrix radiation (both continuous and discrete), a reduction in this background could improve the lower limits of detection. (b) Further, a number of uranium spectral lines, proximate to impurity lines, could be reduced in intensity and thus provide for easier visual intensity estimation of the impurity lines.

Essentially, the problem in this phase of methodological development centers around creating a phemonenon in which the impurities are brought into the excitation system in greater volume than in the previous method, without introducing a proportional amount of uranium matrix. Excitation control and, therefore, background can be reduced to some degree by characterizing the spark column through the selection of source parameters; but, with currently available sources, this is a limited effect. Shorter excitation periods have a serious effect on detection limits; although, ostensibly, the background is diminished.

In the light of extensive experience at the Oak Ridge $Y-12$ Plant $(c)$ in the use of carriers for analyzing uranium, it was determined that the proper approach to the problem was one in which the impurities in and near the analytical surface would be "sensitized" by converting them to volatile forms, while the matrix would convert to a relatively nonvolatile form. Ammonium bifluoride was selected as the sensitizer after the completion of initial studies, the selection being based on such considerations as performance, economics, and contamination.

(b) King, H. G.; In-Situ Characterization of Common Impurities in Uranium Metal by Spark Spectrochemistry, Y-1937; Union Carbide Corporation-Nuclear Division, Oak Ridge Y-12 Plant, Oak Ridge. Tennessee; March 29, 1974.

(c) Operated by the Union Carbide Corporation's Nuclear Division for the US Energy Research and Development Administration. 


\section{CHARACTERIZATION OF URANIUM METAL}

\section{EQUIPMENT}

\section{Spectrograph}

The spectrograph used has a large quartz prism mounted after the manner of Littrow. The 30-degree reflecting prism is illuminated by parallel light from the collimator. The latter receives radiation from the spark column center which is focused on its front surface. After passing the condenser and slit, light from the spark is deviated from being perpendicular to the principal optical axis to a position that is parallel to the principal axis by mcans of a 90-degree reflecting prism. I he camera is arlyled with respect to the principal axis to adjust to the very valuable polychromatic properties inherent in the Littrow mount. This tilt in the camera to achieve focus at the different wavelengths accounts for much of the dispersion so necessary in dealing with complex spectra. A flat sparking table with a counterelectrode clip is mounted on the optical bench to support the part. Alternatively, the cantilever optical bench can be used. (b) Figure 1 is a schematic drawing of the spectrograph; the operating parameters for the instrument are listed in Table 1.

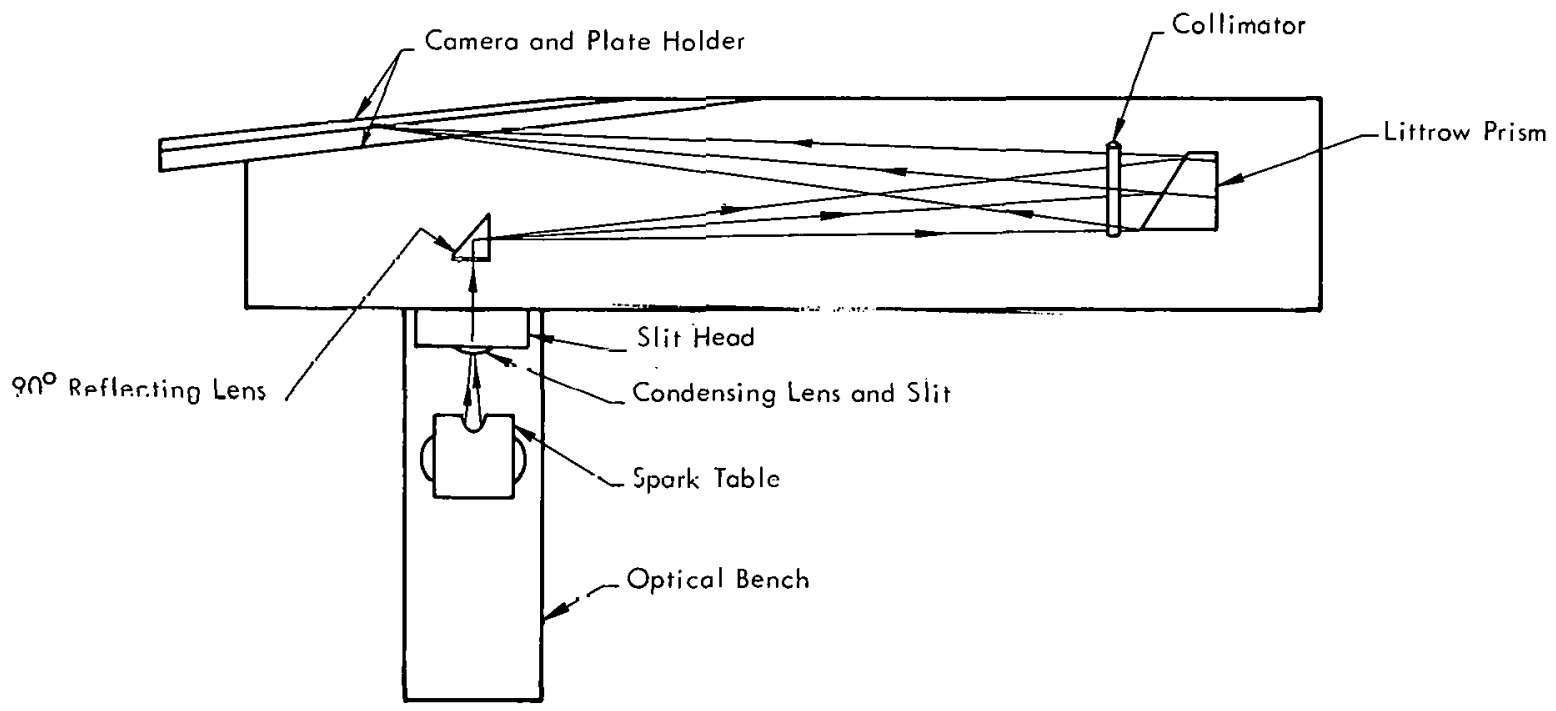

Figure 1. ARRANGEMENT OF THE PRINCIPAL COMPONENTS OF THE SPECTROGRAPH.

Table 1

INSTRUMENT PARAMETERS

\begin{tabular}{ll}
\hline \multicolumn{1}{c}{ Spectrograph } & \multicolumn{1}{c}{ Source Unit } \\
\hline Focus - $153.5 \mathrm{~cm}$ & Voltage $-24,000 \mathrm{~V}$ \\
Camera Tilt - 208 (plutractor setting) & Current $-1.5 \mathrm{~A}$ (in primary) \\
Prism System - Quartz-9 & Capacitance $-0.0063 \mu \mathrm{F}$ \\
Collimator - medium & Inductance $-500 \mu \mathrm{H}$ \\
Slit $-10 \mu \mathrm{m}$ & Spark Power -8 (arbitrary units) \\
Plate - SA-I & Discharges $-4 / \mathrm{half} \mathrm{Hz}$ \\
Exposure $-45 \mathrm{~s}$ & Resistance -5 ohms \\
\hline
\end{tabular}




\section{Source Unit}

The source unit for the work is a condensed RF spark manufactured by the National Spectrographic Laboratories. The maximum potential of the source is 25,000 volts. As much as $0.0063 \mu \mathrm{F}$ of capacitance and $600 \mathrm{mH}$ of inductance can be added. The source is equipped with an auxiliary gap interrupted by an air stream. Breaks per half cycle are adjustable over a range from two to twelve. The interrupter gap is adjustable to provide for changing the break-down potential and for phasing. The spark character can be observed on an oscilloscope mounted on the front panel. Table 1 also gives the operating parameters for the unit.

\section{MATERIALS}

The following materials were used in the investigation:

Uranium metal standards.

Wipers, paper.

Spectroscopic photographic plate, Eastman Kodak Type SA-I.

Photographic Supplies:

Developer, D-19, Eastman Kodak;

Fixer, Eastman Kodak.

Electrodes, spectroscnnic, Carbon Products Division, UCC:

Cathode, graphite, crater $4 \mathrm{~mm}$ by $4 \mathrm{~mm}$ deep in nominal $0.25 \mathrm{in}(6.34 \mathrm{~mm})$ stock, undercut;

Boiler cap, graphite, to fit the graphite cathode.

Reagents:

Methanol, reagent grade;

Ammonium bifluoride, Bakers analyzed grade or Fisher;

Silver fluoride, carrier grade;

Hydrofluoric acid, electronic grade;

Potassium fluoride, Bakers analyzed;

Aretic acid, reagent grade.

\section{EXPERIMENTAL PROCEDURE}

\section{General Considerations}

The classical spectrographir. spark discharge is characterlzed by a number of phenomena, two of which are prominent. First, is the very high thermoelectrical equivalent temperatures encountered in the spark; second, is the ionization power which it displays both in the spark 
column and on the surfaces from which it emanates and impinges. The spark, running at a potential of $25,000 \mathrm{~V}$, can have electron temperatures in the order of about $10^{70} \mathrm{C}$, according to the following calculation:

$$
\mathrm{I} \approx \frac{2}{3} \frac{m v^{2}}{K}
$$

or:

$$
T:\left(\frac{10^{-28} \times\left(10^{10}\right)^{2}}{1.4 \times 10^{16}}\right)^{2 / 3}
$$

where $m \approx 10^{-28}$ gram, the mass of an electron traveling at a velucity, $v$, of $10^{10} \mathrm{~cm} / \mathrm{s}$ and $K\left(1.4 \times 10^{-16}\right)$ is the Boltzmann constant.

This value can be reported, conventionally, as the thermal environment required for 0.025 $\mathrm{MeV}$ electrons. The impact from these electrons can eject material from a part surface for excitation in the spark column. The ionization processes prevalent in the spark give rise to high-energy spectral lines which appear in a spectral region characteristic of such lines (ie, the ultraviolet and far ultraviolet).

These features of the spark have made it useful through the years in the spectrographic analysis of metals for matrix and submatrix elements, and more recently in the analysis of uranium metal for micro amounts of impurities. The latter uses source parameters (principally inductance) to generate additional amounts of vapor.

As in virtually all spectrographic analyses for residuals in a base metal, it is desired to excite as much of the impurity as needed, while holding the spectrum of the matrix to a minimum. Since the source parameters are optimal, the next step in the advancement of the methodolngy for the spark analysis of uranium metal is to arrange for the condition just described to prevail.

\section{Preliminary Investigations}

It bccame apparent after some study that some chemical effect at the part surface could increase the volatility of many of the elements present. Such an effect should be similar to one phase of carrier distillation. The Y-12 Plant Laboratory has had long and extensive experience with carrier techniques; and, although carriers have been used in analyzing uranium in the form of the octoxide $\left(\mathrm{U}_{3} \mathrm{O}_{8}\right)$, there was no immediate reason seen why a carrier should not be used in the analysis of the metal.

Most carrier methods are characterized by three properties: (1) a. "sweeping" action to carry vapor to the excitation site, (2) a suppression of the complex matrix spectrum, and (3) the formation of volatile compounds by chemical action between the elements sought and the carrier. For the purposes of this study, the latter action is the more important, since the goal is to sensitize the uranium part surface by such a process. 


\section{Methodology}

Generally speaking, the volatile compounds of metals are the halides, particularly the fluorides. Table 2 lists the boiling points of the fluorides of the impurity elements, along with the boiling point of uranium tetrafluoride $\left(U F_{4}\right)$. The boiling points and sublimation temperatures of the fluorides are well below that of $\mathrm{UF}_{4}$.

The first approach to sensitization was to apply a thin coat of $5 \%$ electronic-grade hydrofluoric acid to the metal surface, sparking when the surface was dry. However, this approach was found to be unsatisfactory. The layer was quickly and massively removed from the surface, and the latter suffered considerable etching. At this point it was obvious that the sensitization must be effected during the sparking period, that it should proceed at the optimum speed, and must be continuous during the cycle.

The conditions stated can be obtained in two ways: (1) hydrogen fluoride gas can contact the surface of the part by passing from a storage vessel through a tube, or (2) a fluoride compound can be volatilized from a crater in the cathode and react with the part surface during the excitation cycle. The latter course of action was taken.

The second attempt in surface sensitization was made with potassium fluoride. Using crater charges of 20 to $50 \mathrm{mg}$, there was insufficient vapor produced from the high-boiling material $\left(1500^{\circ} \mathrm{C}\right)$ to effect a satisfactory sensitization. Experiments with silver fluoride succeeded in producing a considerable reduction in background intensity and, at the same time, there was an increase in the impurity line intensity. However, $\mathrm{AgF}$ is expensive, and there is the possibility of silver contamination. Ammonium bifluoride was found to be eminently satisfactory for the procedure. Forty milligrams of this sensitizer were packed in the 4 by 4-mm craters of the cathodes; and, after a two-hour period of desiccation, were used to spark the surface of the uranium metal standard parts. Figure 2 provides a comparison of the backgrounds of the method with that of the usual graphite spark, while Figure 3 indicates the sensitivity differences. By observing the line intensities of the lowest standard in both spectra (Figure 3), it can be seen that there has been a sensitivity increase in the elements which fall in this spectral region. The lines used for analysis are given in Table 3; a detailed procedure is given in the Appendix.

\section{Sensitization Phenomenon}

Immediately after the spark begins to operate, the electrode temperatures begin to increase rapidly due to the inductance $(500 \mathrm{mH})$ placed in the internal power circuit. At a relatively low temperature of about $200^{\circ} \mathrm{C}$, the $\mathrm{NH}_{4} \mathrm{HF}_{2}$ begins to vaporize into the spark column and is carried to the part surface being sparked. Following this, and as the interrupter gap spacing is being adjusted, the cathode suffers a current overload at which point in time it is carrying maximum ion and electronic current. The indication of this occurrence is that the cathode becomes acoustic; ie, it begins to "hiss" in much the same manner as the DC arc at the overload point. The spark under these conditions has good stability as, incidentally, does the DC arc.
Table 2

BOILING POINTS OF THE IMPURITY FLUORIDES

(All Values in ${ }^{\circ} \mathrm{C}$ )

\begin{tabular}{lc}
\hline $\mathrm{CuF}_{2}$ & $\sim 1000(1)$ \\
$\mathrm{FeF}_{2}$ & $\sim 1050^{(1)}$ \\
$\mathrm{MoF}_{6}$ & 35 \\
$\mathrm{NbF}_{5}$ & 236 \\
$\mathrm{NiF}_{2}$ & $\sim 800^{(1)}$ \\
$\mathrm{SiF}_{6}$ & 86 \\
$\mathrm{TiF}_{4}$ & 284 (sublimes) \\
$\mathrm{ZrF}_{4}$ & 600 (sublimes) \\
$\mathrm{UF}_{4}$ & 1477 \\
$\mathrm{UF}_{6}$ & Not Likely to be \\
& Tormed
\end{tabular}

(1) Estimates only. 


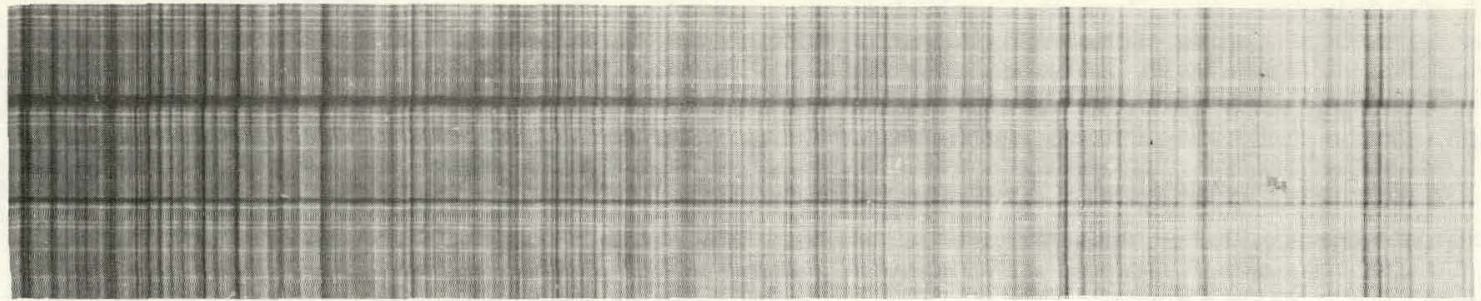

C

(a) Conventional Graphite Spark. (3X)

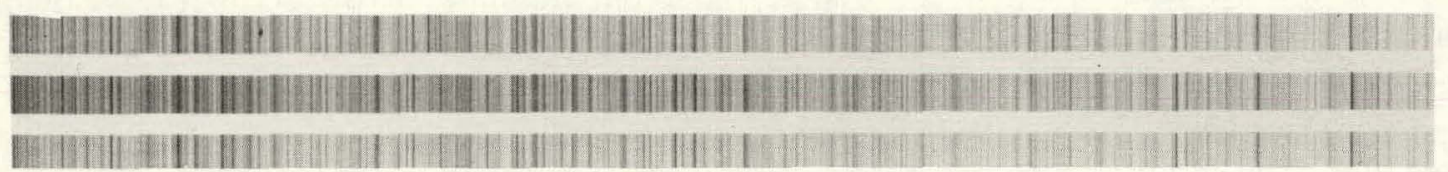

C

(b) Surface Sensitization. (2.8X)

Figure 2. BACKGROUND COMPARISON.

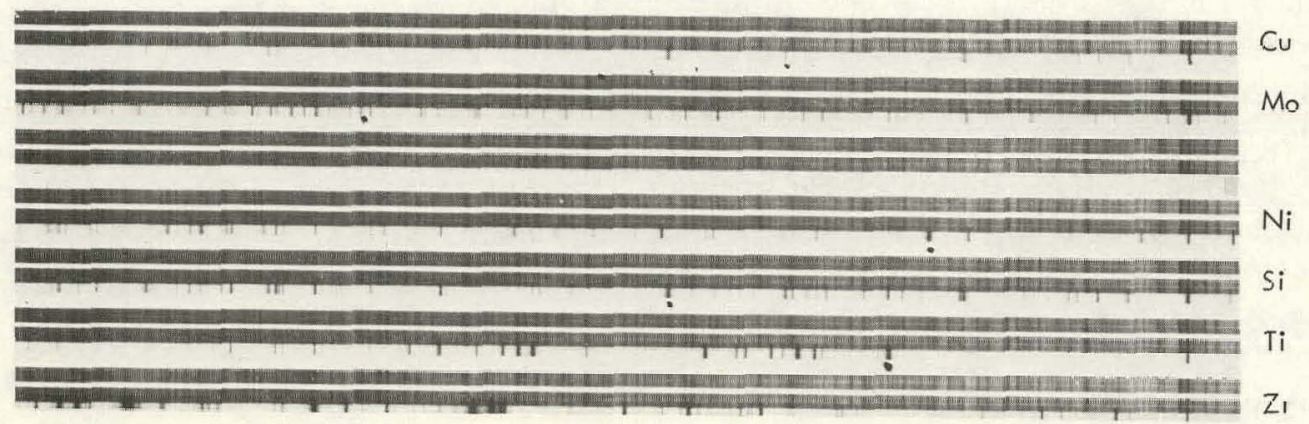

(a) Conventional Graphite Spark. (2.5X)

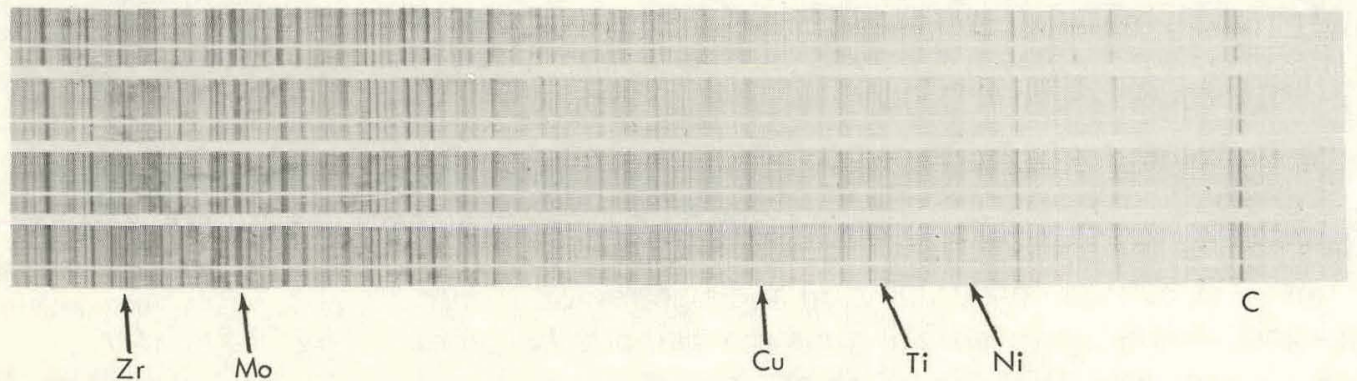

(b) Surface Sensitization. (3X)

Figure 3. LINE-INTENSITY COMPARISON. 
The chemical action proceeds at the part surface, and the sensitization occurs with this action, whereby the volatile fluorides of such metals as iron, copper, nickel, and silicon are vaporized into the spark column. The uranium compound formed which is most likely UF $_{4}$ appears not to vaporize too readily, as is indicated in Spectrum b of Figure 2. Electron microprobe studies of the sensitized areas before and after sensitizing and sparking are illustrated in Figure 4. It is indicated that there is a chemical effect, as can be seen from a comparison of the two views of Figure 5 . View $b$ shows an area sparked with a simple graphite rod cathode. When the impurity level is low, the sensitization occurs principally in the metal crystal structure; since, at low impurity levels, the grain boundaries are small. Figure 6 shows a sensitized zone of a low-impurity-level standard and the area in this zone on which the spark impinged. Figure 7 shows a sensitized sparked area at low magnification, showing the effect on the metal surface.

\section{DISCUSSION}

From the spectra displayed in Figure 3 it can be seen that the exposure, $\mid t^{n}$, could be increased by a factor of two without serious effects in the background. This effect could lead to a further increase in the sensitivity of the method.

No photoelectric measurements were made to compare the line intensities of the method described with the current method. However, if the low standards are visually compared it can be seen that there is an increase in sensitivity of from 1.5 to 2.0 times over the current method. Figure 3 shows a series of pairs of exposures of the lowest and highest level standards with a one-impurity element spectrum beneath each high-level standard for identification of the characteristic lines.

During the sparking cycle, the grain hnundaries of the higher-level standards empty to an average depth of 22 micrometers. In the low-level standards, this measurement could not be made since the delineation is small. In the high standards, when the impurity concentrations exceed their solubility in uranium, there is an accumulation in the grain boundaries which can then be readily observed. It was predicted that the effect on the small boundaries would be similar to that on the impurity-filled boundaries, although an electron microprobe scan across the small boundaries could not show changes in the impurity levels because the concentration levels in the low standards were too low for detection by the probe.

When affected zones of specimens sparked by the technique are polished to a depth of 25 micrometers, the newly generated surface is bright and not deformed. Corrosion-resistant centers have been formed by the sensitizer and spark, which indicates refining of the metal at a greater depth than the topography disturbances show. Two of the specimens suffered no corrosion in air after several weeks. 

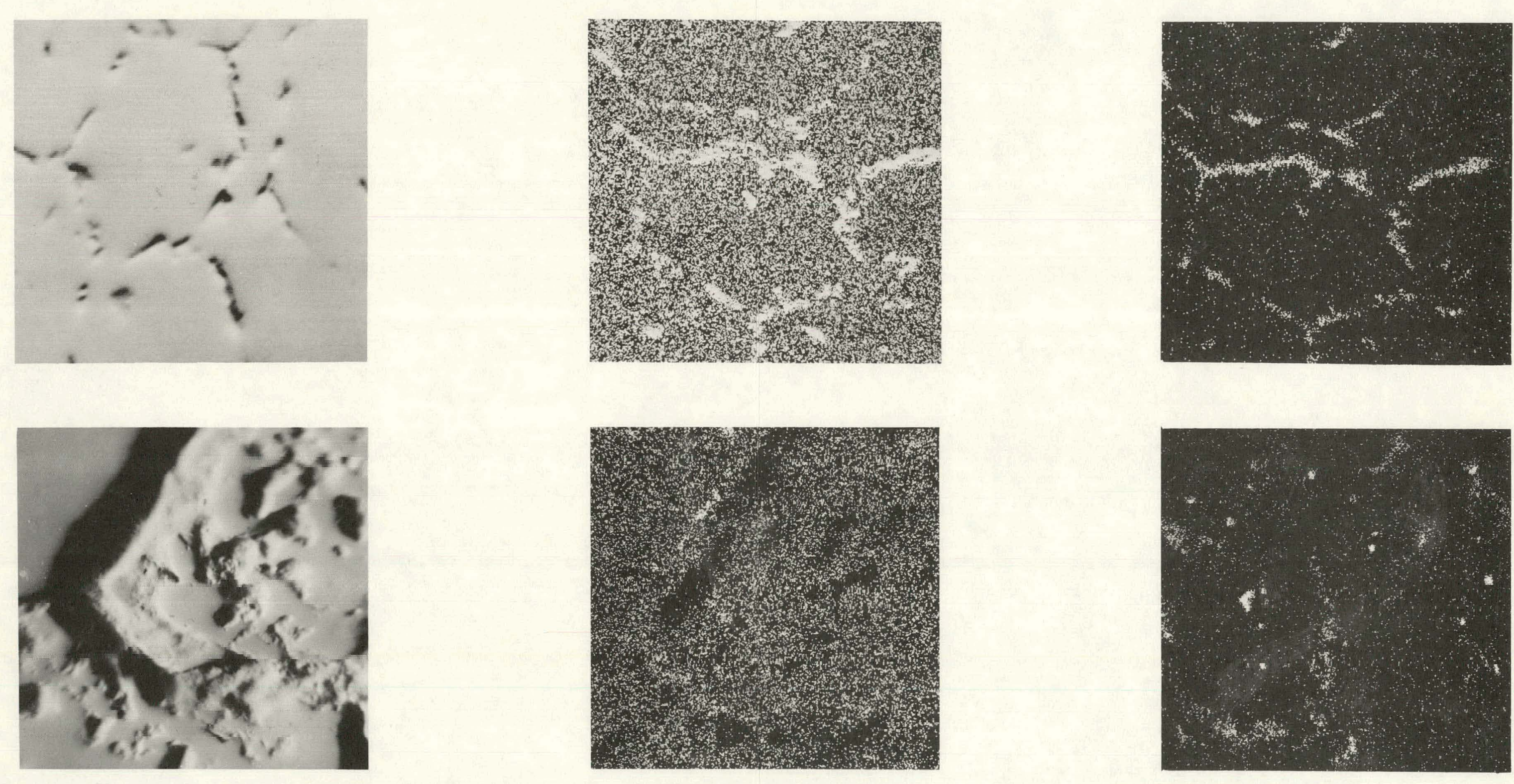

(b) X-Ray Videogram of $\mathrm{Fe} \mathrm{K}_{\mathrm{c}}$

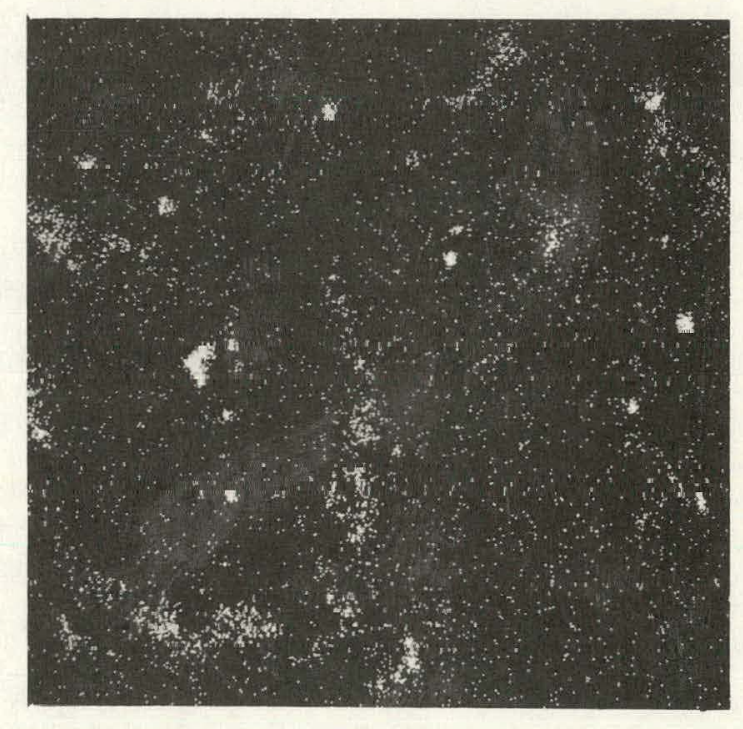

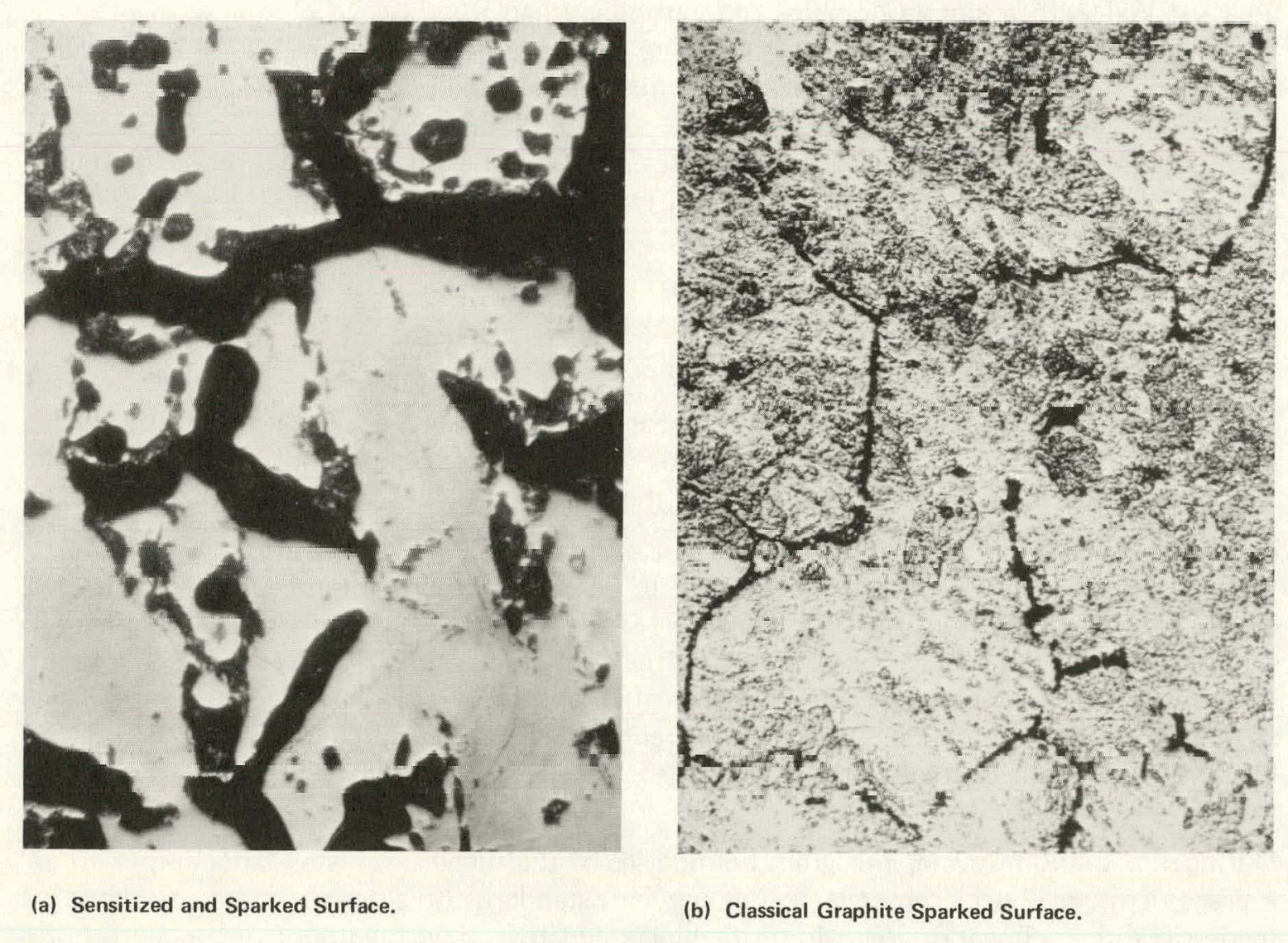

rigure 5. TWO SURFACES SHOWING A CHEMICAL EFFECT.

Figure 4. IRON AND SILICON URANIUM METAL STANDARDS. [Top Views were Taken before Sparking, Bottom Views were Taken after Sparking (sensitized); 300x] 


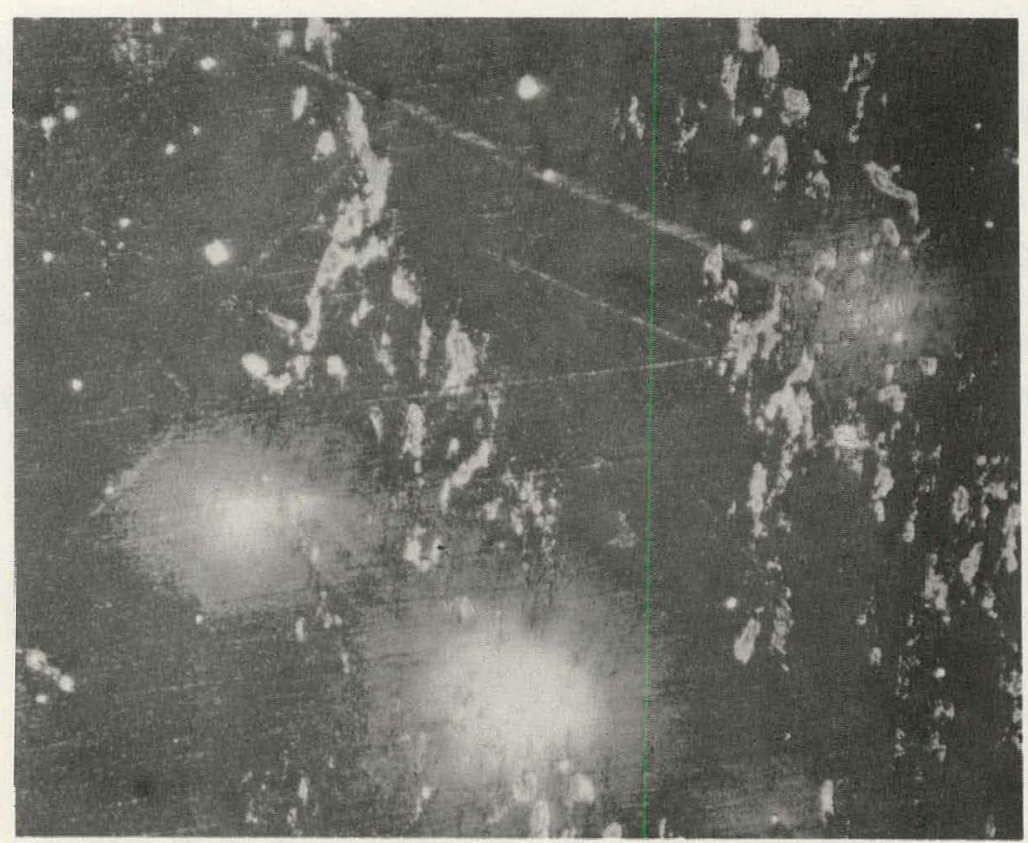

(a) Sparked Area.

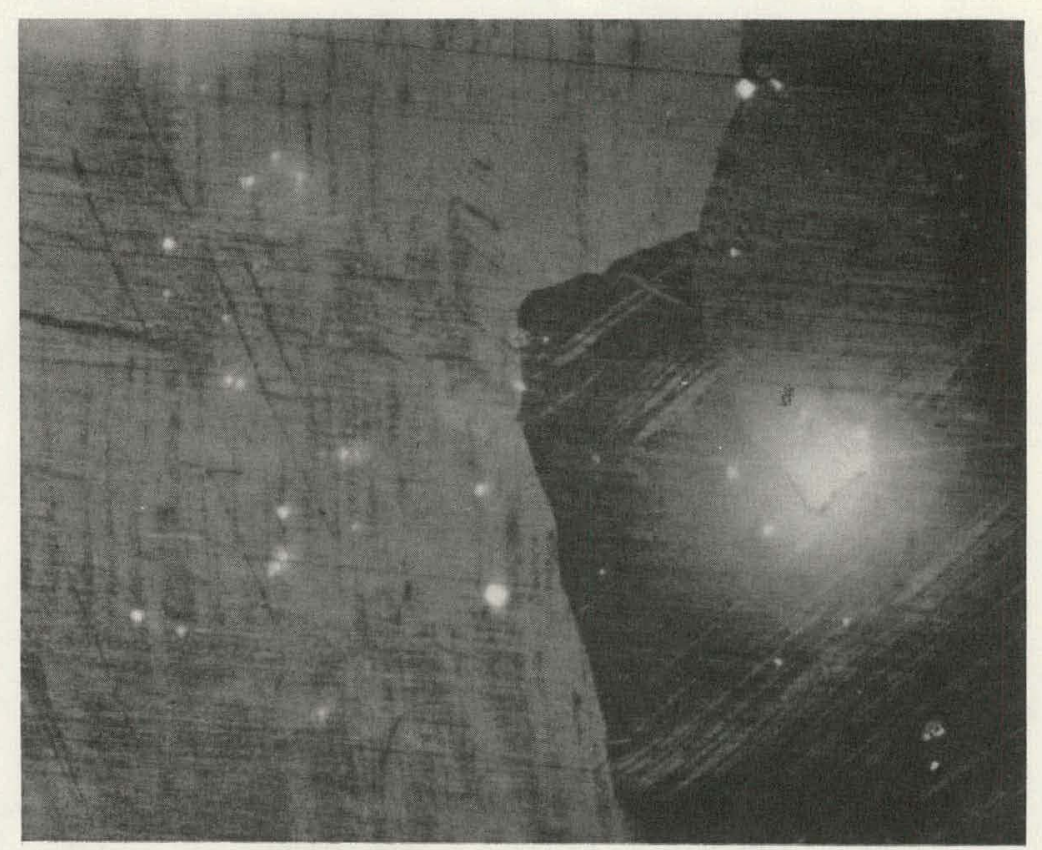

(b) Sensitized Area Adjacent to the Sparked Area.

Figure 6. OPTICAL PHOTOGRAPHS OF A LOW-IMPURITY-LEVEL URANIUM STANDARD. (190X) 


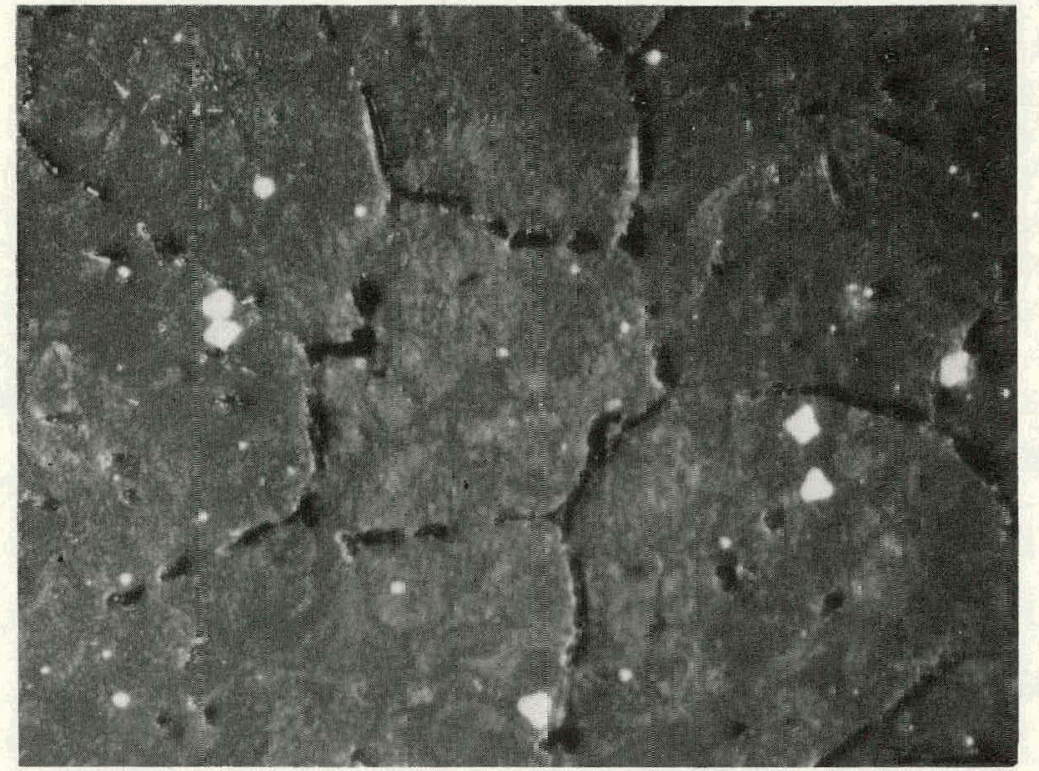

(a) At 190x.

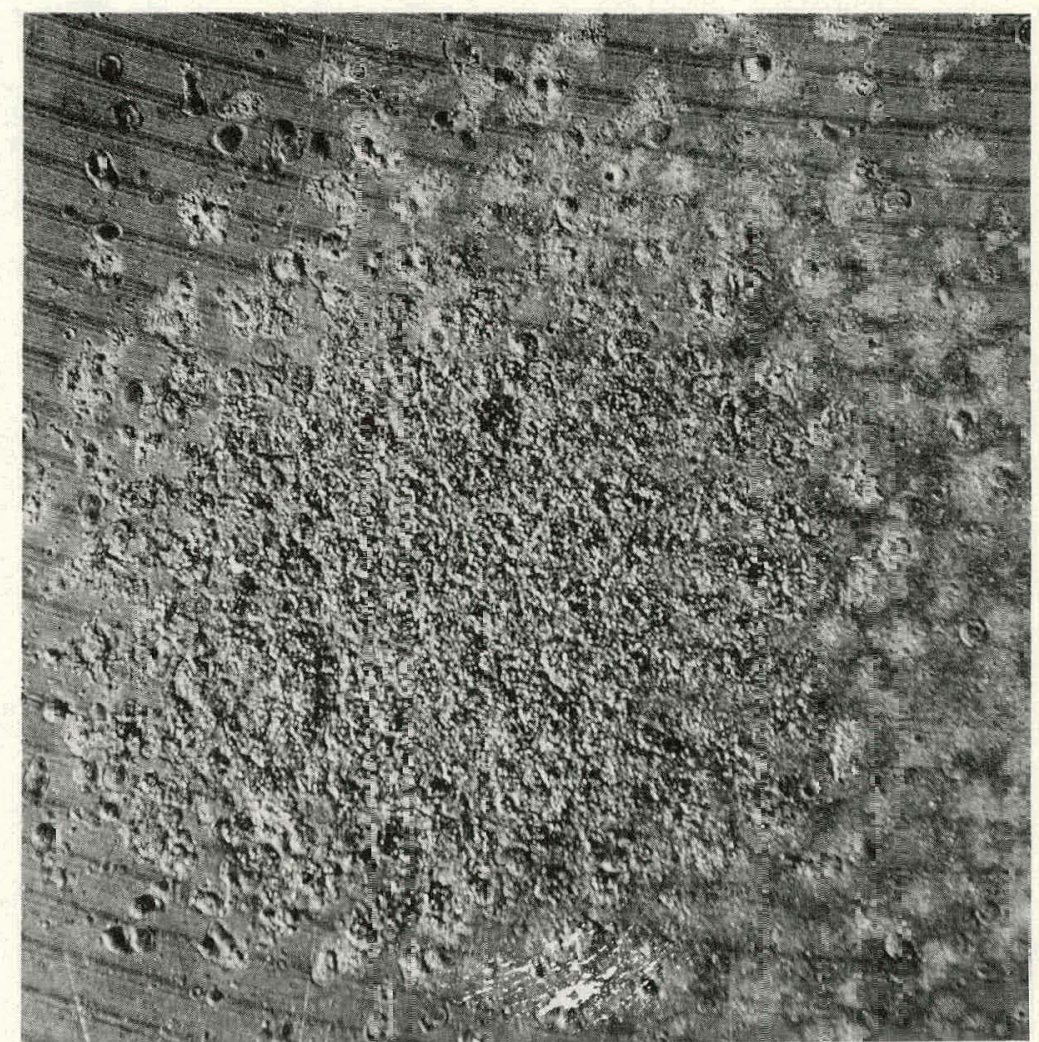

(b) At 10X.

Figure 7. A SENSITIZED SPARKED SURFACE AREA AT TWO MAGNIFICATIONS. (Optical Views) 


\section{CONCLUSIONS AND RECOMMENDATIONS}

The surface carrier-sensitizer procedure for the spark spectrographic analysis of uranium metal and uranium parts with tolerances up to 50 micrometers $(0.002 \mathrm{in})$, which is twice the metamorphosed depth, involves a feasible methodology which produces a more readable spectrum and increased sensitivity over current procedures of this type.

This procedure is recommended in situations where it is necessary to furnish analytical information concerning allowable impurity levels lower than the specification limits, but higher levels than that obtained by the refined carrier distillation technique applied to $\mathrm{U}_{3} \mathrm{O}_{8}$ samples. In this method, copper, molybdenum, niobium, and nickel are seen at $10 \mathrm{ppm}$; titanium, under $4 \mathrm{ppm}$; zirconium, well under $50 \mathrm{ppm}$; and iron easily at $20 \mathrm{ppm}$. These levels should be adequate for more conservative process control.

The elements studied in this work are those in which a particular interest has been shown. The possibility of determining additional elements has not been pursued, but it seems likely that a number of other impurities could be determined by the method. 


\section{ACKNOWLEDGEMENTS}

The author wishes to express his appreciation for the able assistance given him by C. D. Stevenson and J. R. Ferguson of the Y-12 Plant Laboratory Electron Microprobe Section, and J. E. Ferguson and C. L. Quimby of the $\mathrm{Y}-12$ Laboratory Development Department. A special word of appreciation goes to C. M. Neff, supervlsur ur llie Spectrographic Laboratory, for his advice and assistance. 


\section{APPENDIX}

\section{IN-SITU SPARK SPECTROCHEMICAL CHARACTERIZATION OF URANIUM METAL BY ANODE SENSITIZATION}

A. Preparation of the instruments.

1. Inspect the area surrounding the instrumentation for safety of operation and cleanliness.

2. Set the source unit parameters to the values given in Table 1, and energize the unit.

3. Set the parameters for the spectrograph, as given in Table 1.

4. Load an SA-I spectroscopic plate in the plate holder and slide the holder into the camera.

B. Cleaning the part.

1. Carefully wipe the surface area to be sparked with a cellulose wiper.

2. Apply 10 to $15 \mathrm{ml}$ of a solution of methanol-5\% acetic acid and rub the area briskly.

3. Rinse the surface thoroughly with distilled water.

4. Dry the surface completely with a wiper.

C. Operational procedure.

1. Weigh $40 \mathrm{mg}$ of $\mathrm{NH}_{4} \mathrm{HF}_{2}$ into a 4 by $4-\mathrm{mm}$ undercut crater in a nominal $6.35-\mathrm{mm}$ by $63.5-\mathrm{mm}$ long graphite electrode, and tamp the charge lightly with a $3.18-\mathrm{mm}$ graphite rod.

2. Place the electrode in a desiccator for two hours.

3. When properly desiccated, fasten the electrode in the $V$ slot beneath the spring clips of the spark stand cathode.

4. By pressing the bottom of the electrode, bring the crater lip up to the level of the table and firmly place the boiler cap over the crater.

5. Bring the gap spacer, which is located on the right front corner of the table, gently down on top of the cap.

6. Holding the ring or little finger of the left hand on the bottom of the electrode and, with the fore and middle fingers over the spring clips, press down on the spacer to achieve a proper analytical gap. 
7. Carefully place the part on the table with the cleaned area centered over the boiler cap. Note: In the event that the surface to be sparked is round, place nonconducting wedges or blocks on both sides of the table top to bring the circumference of the part tangent to the plane of the sparking table top.

8. Pull the dark slide on the plate holder to the "open" position and set the camera of the spectrograph in position to receive the first exposure.

9. Throw the spark control switch to the "on" position and press the "start" button.

10. Readjust the part to obtain a fresh surface and repeat Step 9.

11. After two exposures, immediately remove the part trom the table and clean it thuruughıly willı nellianol and paper wipers.

12. Spark the standards at the bottom of the plate.

13. Develop, fix, and dry the SA-I plate and compare the impurity lines of the samples with those of the standards. 
Distribution

Energy Research and Development Administration - Oak Ridge

Hickman, H. D.

Leed, R. E.

Zachry, D. S., Jr

Oak Ridge Gaseous Diffusion Plant

Wilcox, W. J., Jr

Winkel, R. A.

\section{Oak Ridge Y-12 Plant}

Bernander, N. K.

Briscoe, O. W.

Burditt, R. B.

Burkhart, L. E./Rowan, J. H.

Cole, S. H.

Fraser, R. J.

Harman, W. D.

Harris, F. W.

Jones, F. W.

Kahl, K. G.

Keith, A.

King, H. G. (10)

Kite, H. T.

Lundin, M. I.

McLendon, J. D.

Mills, J. M., Jr

Morrow, R. W.

Neff, C. M.

Parker, J. C.

Phillips, L. R.

Schreyer, J. M.

Smith, H. F., Jr

Smith, R. D.

Tewes, W. E.

Thưnason, J. C.

Weathersby, W. E.
Williams, R. W.

Yaggi, W. J./Googin, J. M.

Y-12 Central Files (5)

$Y-12$ Central Files (master copy)

$Y-12$ Central Files (route copy)

$\mathrm{Y}$-12 Central Files (Y-12RC)

Zerby, C. D.

Paducah Gaseous Diffusion Plant

Levin, R. W.

In addition, this report is distributed in accordance with the category UC-4, Chemistry, as given in the USERDA Standard Distribution Lists for Unclassified Scientific and Technical Reports, TID-4500. 